\title{
Taxonomic review of the umbelliferous taxa Heracleum moellendorffii complex in Korea based on molecular phylogenies of nuclear ribosomal ITS sequences
}

\author{
Byoung Yoon Lee*, Chae Eun Lim, Jong-Hak Yun, Jung-Hyun Kim, Sun-Yu Kim and Jeong Eun Han \\ Division of Plant Resources, National Institute of Biological Resources, Incheon 404-170, Korea \\ *Correspondent: bylee80@korea.kr
}

\begin{abstract}
Taxonomy of umbelliferous taxa Heracleum moellendorffii complex has been unclear in their species delimitation in the far-eastern Asian regions. In both Korea and China Heracleum moellendorffii was adopted for their description while H. sphondylium was chosen to describe Japanese Heracleum. From Genbank accessions, taxa collected from Kamtchatka and Promorskiy, Russia were defined as H. maximum, endemic taxon to North America. In this study, we reviewed the taxonomy of Heracleum moellendorffii complex in Korea and neighboring countries on the basis of molecular phylogenies derived from sequences of nuclear ribosomal DNA internal transcribed spacer(ITS) regions. From three Korean accessions of Heracleum investigated in this study, two types of ITS sequences were obtained; two accessions were related to Chinese H. moellendorffii var. moellendorffii and North American H. maximum without forming a clade while the other one was identical to accession from $H$. maximum from Primorskiy, Russia. In the other hand, Japanese H. moellendorffii (=H. sphondylium ssp. sphondylium var. nipponicum in the flora of Japan) was closely related to H. maximum accessions from Korea and Russia, not nested within the clade comprising several subspecies of $H$. sphondylium. In order to delimit species boundaries among putatively closely related Heracleum species in fareastern Asian countries, more samples and much more rapidly evolved DNA regions must be investigated with interpretation of morphological and anatomical features.
\end{abstract}

Keywords: Apiaceae, Heracleum maximum, Heracleum moellendorffii, Umbelliferae

\section{INTRODUCTION}

The genus Heracleum L. belongs to the family Apiaceae (=Umbelliferae), and is distinguished from other umbel genera by characteristics such as fruit vittae with short and clavate shapes, not extending to the base of fruit, markedly enlarged bifid outer petals, thickened lateral mericarp wings with rigid margins (She et al., 2005). The genus Heracleum comprises about 65 to 120 species that often live in open forest areas (Pimenov and Leonov, 1993; Lee, 2007). Most species of the genus Heracleum are Eurasian with the Sino-Himalayan and Caucasus regions considered to be major centers of biological diversity (Pimenov and Leonov, 1993; Ma et al., 2005; Yu et al., 2011). Numbers of Korean Heracleum taxa were different depending upon taxonomist's opinions. Lee (1980) and Lee (2007) reported just single species, H. moellendorffii while Lee (1996) recognized two varieties of $H$. moellendorffii Hance; var. moellendorffii and var. subbipinnatum (Franchet) Kitagawa (=H. moellendorffii for. angustum). However, $\operatorname{Im}(1998)$ reported three taxa vege- tated in Korea, two varieties of $H$. moellendorffii Hance (var. moellendorffii, var. subbipinnatum (Franchet) Kitagawa) and $H$. dissectum Ledeb. While the number of Heracleum taxa in Korea were counted by three (Im, 1998; She et al., 2005), just one speices, was described in other Korean flora (Lee, 1980; Lee, 2007) and recognized in both Korean plant names index (http://www.nature.go.kr /kpni) and National list of species of Korea (Vascular plants) (Lee et al., 2011). Heracleum moellendorffii is distributed widely in Asia and has long been regarded as a taxonomically complex with three varieties commonly recognized: var. moellendorffii, var. subbipinnatum (Franchet) Kitagawa, var. paucivittatum R.H. Shan \& T.S. Wang. Heracleum moellendorffii var. moellendorffii can be distinguished from var. subbipinnatum by the presence of broadly ovate leaves in outline, with ultimate segments broad to ovate ( $\mathrm{Pu}$ and Watson, 2005). In the other hand, var. subbipinnatum is characterized by elliptic leaves in outline, with ultimate segments ovate to lanceolate. Although three varieties of $H$. moellendorffii have been suggested, their taxonomic status and positions have not been investigated in detail until the recent phylogenetic and 
biogeography studies of Chinese Heracleum were conducted by Yu et al. (2011). Heracleum dissectum reported from Korea is distinguished from $H$. moellendorffii by the presence of basal and lower leaves with 1-2 pinnate dissection, triangular but minute calyx teeth, vallecular vittae extended to $2 / 3$ the length of mericarps ( $\mathrm{Pu}$ and Watson, 2005). In the far-eastern Asian countries, there have been taxonomic problems in describing the same or similar species of Heracleum. In both Korean and Chinese flora, Heracleum moellendorffii was adopted for their description while $H$. sphondylium or $H$. lanatum $(=H$. maximum) was chosen to describe Japanese Heracleum moellendorffii (Ohba, 1999; Takahashi, 2009). Taxa collected in Kamtchatka and Promorskiy, Russia were defined as $H$. maximum, endemic taxon to North America (data were obtained from the Genbank accessions). Through recent field surveys on Daeam-san in Korea, we found a taxon of Heracleum that was guite different morphologically in radical leaves from other Korean Heracleum taxa. This species that grows in the partly shady mountain woodlands of the mountain has similar leaf characteristics with $H$. maximum in deeply-divided lobes of upper radical leaves. Here, all the possible accessions of Heracleum moellendorffii and its allied taxa have been investigated in order 1) to ascertain their taxonomic status and positions by comparing putatively related speices in neighboring regions, 2) to identify a Heracleum taxon collected in Daeamsan, and 3) to record them in the national species list in Korea. To achieve these objectives, we used the internal transcribed spacer (ITS) of nuclear ribosomal DNA (nrDNA) which have been a particulary valuable marker for phylogenetic interpretation at interspecific level among Apiaceae taxa (Downie et al., 1998; Lee, 1998; Lee and Downie, 1999; Zhou et al., 2008; Lee et al., 2010; Yu et al., 2011).

\section{Materials And Methods}

Nuclear ribosomal DNA internal transcribed spacer

Table 1. Thirty accessions of the genus Heracleum and outgroups examined for nuclear ribosomal DNA internal transcribed spacer sequences (ITS) variation. Ingroup taxa were all Heracleum, and newly investigated sequences start with letters of WIGIS (Wildlife Integrated Genetic Information System; National Institute of Biological Resources, Korea). Acronyms: Genbank Acc. No.=Genbank accession numbers. A taxon collected from Daeamsan was preliminary treated as H. maximum while H. lanatum ssp. moellendorffii collected in Japan (obtained from Genbank) was treated as H. moellendorffii var. moellendorffii due to a synonym treatment.

\begin{tabular}{|c|c|c|}
\hline Taxon name & Source or voucher information & $\begin{array}{c}\text { Genbank/WIGIS } \\
\text { Acc. No. }\end{array}$ \\
\hline H. dissectifolium K.T. Fu & China, Sichuan, Danba, Zhake Village & FJ812141 \\
\hline H. dissectum Ledeb. & China, Xinjiang, Aertai & GU967800 \\
\hline H. fargesii Boiss. & China, Sichuan, Nanchuan & FJ812114 \\
\hline H. forrestii Wolff & Unknown; Paik and Watson (2007) & EU185688 \\
\hline H. franchetii M. Hiroe & China, Sichuan, Xiaojin, Mengbi Shan & FJ812124 \\
\hline H. hemsleyanum Diels & China, Sichuan, Xiaojin, Balangsan & FJ812111 \\
\hline H. maximum $\mathrm{W}$. Bartran & USA, Colorado & EU594924 \\
\hline H. maximum $\mathrm{W}$. Bartran & Russia, Kamtchatka & EU594922 \\
\hline H. maximum $\mathrm{W}$. Bartran & Russia, Primorskiy Kray & EU594923 \\
\hline H. maximum $\mathrm{W}$. Bartran & Korea, Daeamsan & WIGIS004982 \\
\hline \multicolumn{3}{|l|}{ H. moellendorffii Hance } \\
\hline var. moellendorffii & Korea, Gyeonggi-do, Cheonggye-san & WIGIS004981 \\
\hline var. moellendorffii & Korea, Gangwon-do, Taebaek-si & WIGIS004980 \\
\hline var. moellendorffii & China, Sichuan, Xiaojin, Balangsan & FJ812137 \\
\hline var. moellendorffii & China, Shaanxi, Meishan, Taiba Shan & FJ812127 \\
\hline var. moellendorffii & Japan, Honshu & EU594925 \\
\hline var. subbipinnatum (Franch.) Kitagawa & Unknown; Yu et al. (2009) & FJ812134 \\
\hline var. subbipinnatum (Franch.) Kitagawa & China, Gansu, Lianlu, Lianhua Shan & FJ812131 \\
\hline H. souliei Boiss. & China, Sichuan, Kangding-Hailuo gou & FJ812112 \\
\hline \multicolumn{3}{|l|}{ H. sphondylium $\mathrm{L}$. } \\
\hline ssp. montanum (Schleich. ex Gaudin.) Briq. & France, Luchon & EU594907 \\
\hline ssp. sibiricum (L.) Simonkai & Poland, Zyzniewo & EU594910 \\
\hline ssp. sphondylium & Poland, Wigry NP. & EU594906 \\
\hline ssp. sphondylium & Poland, Wigry NP. & EU594905 \\
\hline ssp. sphondylium & France & EU169286 \\
\hline ssp. transsilvanicum (Schur) Brummit & Romania, Fagars & EU594914 \\
\hline H. wenchuanense F.T. Pu et X.J. He & China, Sichuan, Wenchuan, Balang Shan & FJ812122 \\
\hline H. wolongense F.T. Pu et X.J. He & China, Sichuan, Wenchuan, Balang Shan & FJ812142 \\
\hline A. dahurica (Fisch. ex Hoffm.) Benth. \& Hook. & Korea, Gywonggi-do, Gwangdeog-san & JN603213 \\
\hline A. decursiva Benth. \& Hook. & Korea, Chilbosan & JN603215 \\
\hline A. gigas Nakai & Korea, Daegwanryeong & JN603232 \\
\hline A. polymorpha Nakai & Korea, Chiag-san & JN603221 \\
\hline
\end{tabular}


(ITS) sequences of Heracleum taxa were obtained in earlier phylogenetic and biogeographic analyses of the Chinese Heracleum (Yu et al., 2011). In order to confirm taxonomic positions of three Korean Heracleum taxa, we have incorporated ITS sequences of above taxa as well as several accessions of $H$. sphondylium found in Japan. And also, several accessions of Heracleum from Genbank have been incorporated into the data matrix (Table 1). A total of 30 accessions were used to reconstruct molecular phylogenies including four taxa of Angelica as outgroups. Total genomic DNA was extracted from fresh leaves and herbarium preserved tissues using the modified CTAB procedure of Doyle and Doyle (1987). Double stranded DNAs of the complete ITS regions in each genomic DNA were PCR (polymerase chain reaction)-amplified using primers "ITS 5" and "ITS 4" (White et al., 1990). Details of the amplification reactions, purification, and alignment were the same as described in Lee (1998). Pairwise nucleotide differences of unambiguously aligned positions were determined from the distance matrix option in Phylogenetic Analysis Using Parsimony (PAUP*, Swofford, 2000). Phylogenetic analyses of the ITS sequences data

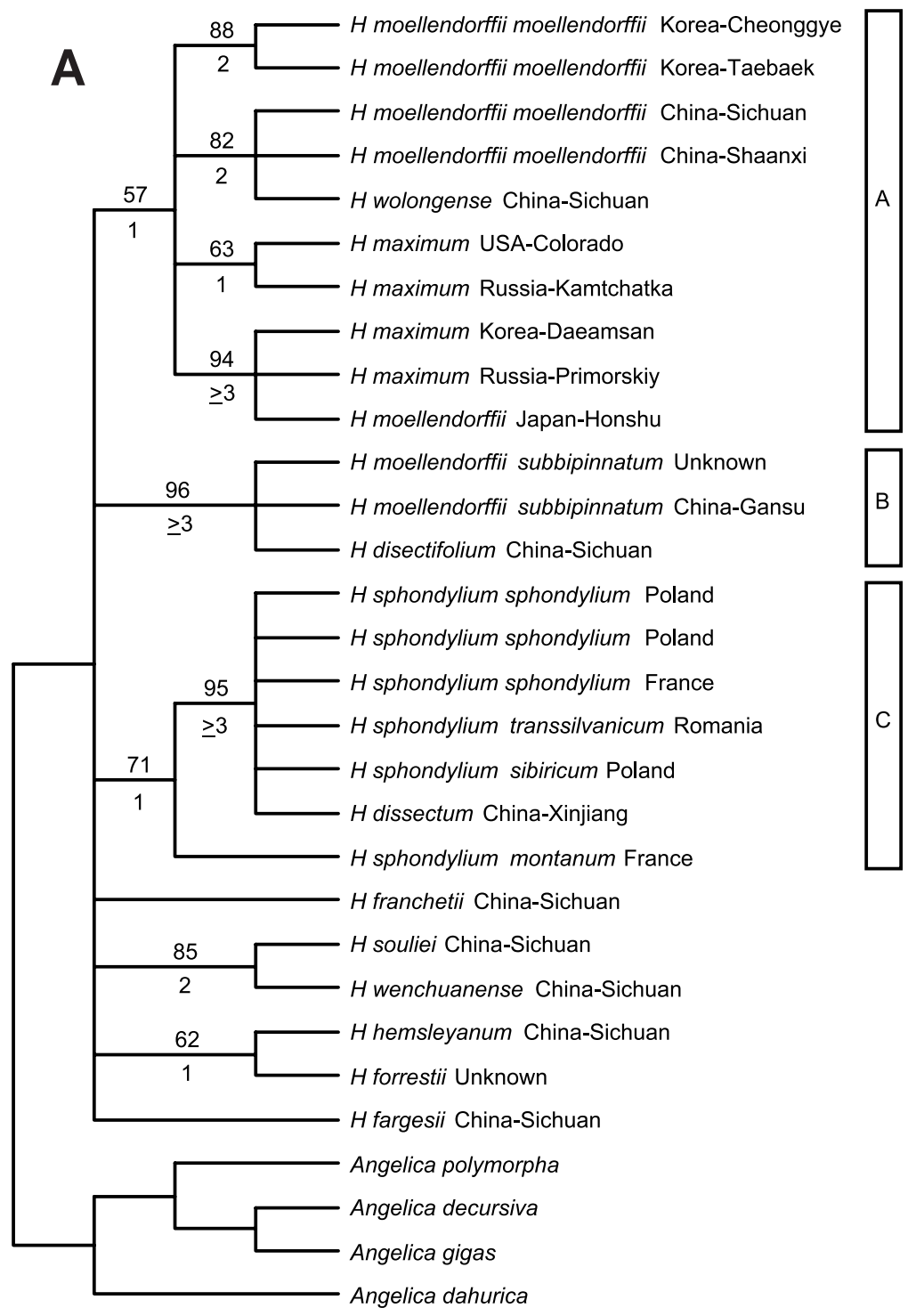

Fig. 1. Cladograms inferred from the analysis of 29 nuclear ribosomal DNA ITS1 and ITS2 sequences from the genus Heracleum and an outgroup. (A) The strict consensus of two minimal length 138-step trees derived from equally weighted maximum parsimony analysis of combined nuclear rDNA ITS and 5.8S sequences (CI's with and without uninformative characters $=0.91$ and 0.89 , respectively; RI=0.95). Numbers above nodes indicate the number of times a monophyletic group occurred in 100 bootstrap replicates; decay values are presented below. (B) The Maximum likelihood tree using a transition/tranversion rate ratio of 1.5. Branch lengths are proportional to the number of expected nucleotide substitutions per site. Boxes A, B, and $\mathrm{C}$ indicate clades $H$. maximum-moellendorffii, $H$. subbipinnatum, and $H$. sphondylium, respectively. 


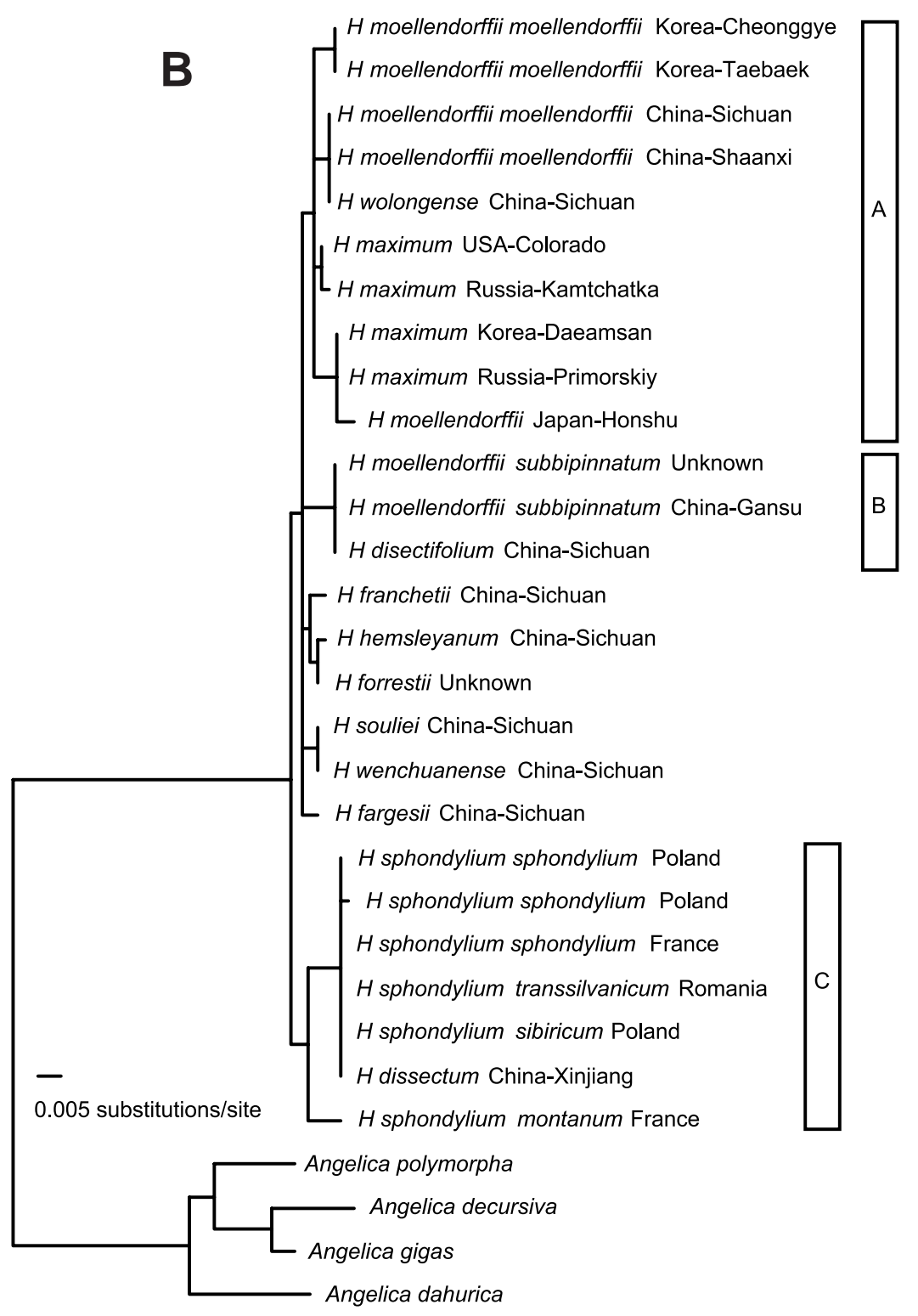

Fig. 1. Continued.

sets were carried out using the heuristic search strategies of PAUP*. All searches were conducted with 100 random-addition replicates using tree bisection-reconnection (TBR) branch swapping. In order to identify weakly supported nodes, decay analyses (Bremer, 1988) were conducted until tree storage memory was exhausted. A bootstrap analysis was done using 100 resampled data sets. In addition to parsimony analysis, maximum likelihood phylogeny estimation using the ITS sequences was explored utilizing PAUP*. A minimum likelihood tree was inferred using a transition/transversion rate ratio of 1.5 , General Search Option. Empirical base frequencies were derived form the sequence data and used in the maximum likelihood calculations.

\section{Results}

\section{ITS sequence analysis}

Alignment of all 30 complete ITS 1, 5.8S ribosome, and ITS 2 sequences, representing all possible accessions of the genus Heracleum and outgroups resulted in a matrix of 604 characters. Overall length of both ITS spacer regions across all 26 ingroup accessions is 602 bp with the exception of $603 \mathrm{bp}$ in $\mathrm{H}$. franchetii. These sizes are comparable to those values reported for other Apiaceae (Downie et al., 1998; Lee and Downie, 1999; Lee et al., 2010). Of the 608 unambiguously aligned positions, four bp were deleted from the data matrix due to alignment 


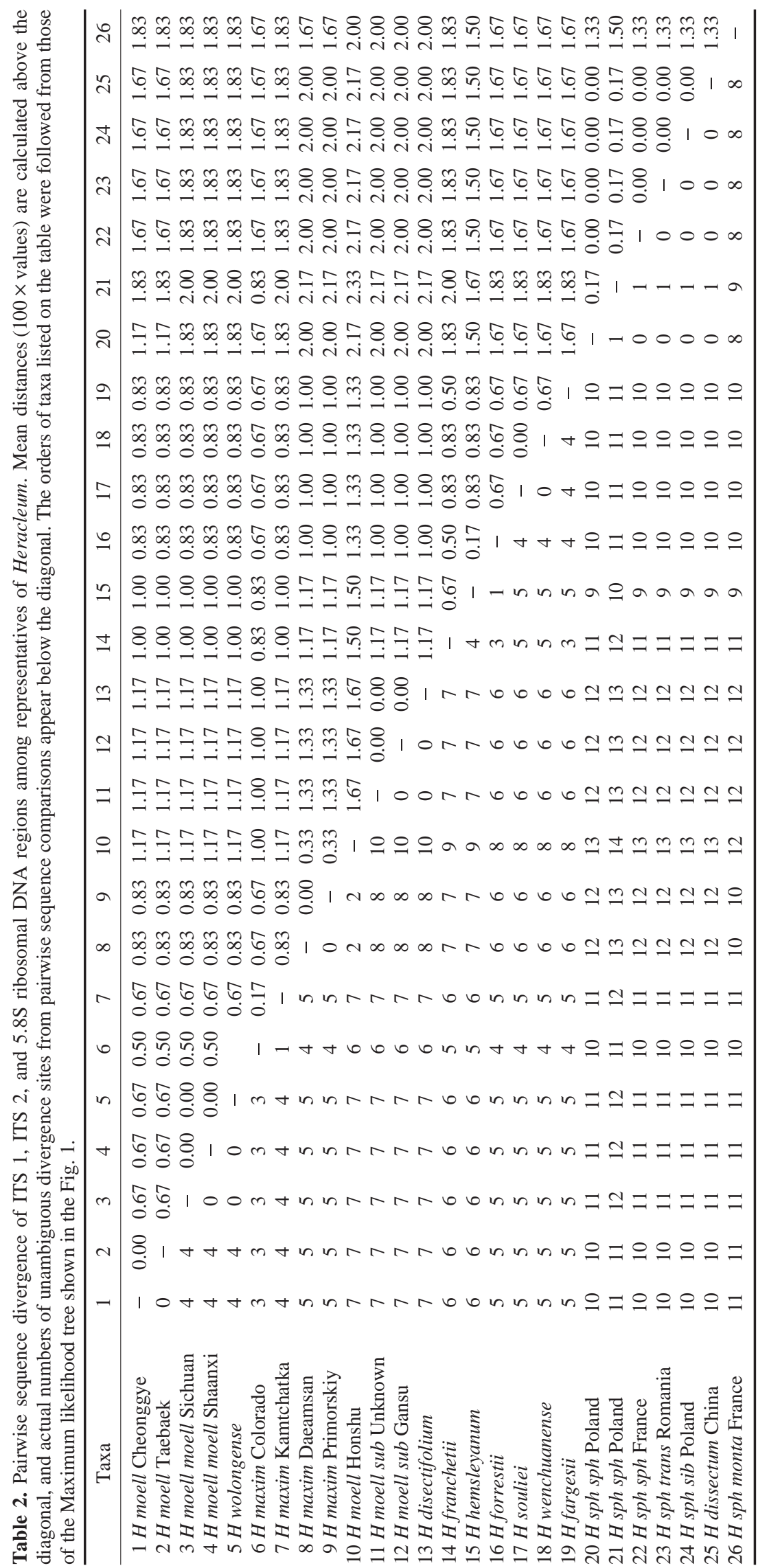


problems. Of the remaining 604 positions, $85(14.1 \%)$ were potentially parsimony informative, $490(81.1 \%)$ were constant, and $29(4.8 \%)$ were autapomorphic. Values of direct pairwise ITS sequence divergence of the examined taxa of the genus Heracleum ranged from identity (between two accessions of $H$. moellendorffii var. moellendorffii from Korea, between two accessions of $H$. maximum from Korea and Russia, between two accessions of H. moellendorffii var. subbipinnatum, and among four accessions of subspecies of $H$. sphondylium, ssp. transsilvanicum, ssp. sibiricum, ssp. sphondylium to $2.33 \%$ between $H$. sphondylium ssp. sphondylium (EU594905) and H. moellendorffii from Japan (Table 2).

\section{Phylogenetic analyses and resolution}

The parsimony analysis of 30 combined ITS and 5.8S ribosomal sequences using equally weighted character states resulted in six maximally parsimonious trees, and the consensus of these trees with accompanying bootstrap and decay values, and is presented in Fig. 1A. In the consensus of these trees, three major groups of taxa can be discernable; but these groups are unresolved with other clades or species, $H$. fargesii and $H$. franchetii. The first group, "A clade" (supported with 57\% of bootstrap values), includes five accessions of $H$. moellendorffii, four accessions of $H$. maximum from Korea, Russia, U.S.A., and $H$. wolongense. The second group, "B clade" (supported with $96 \%$ of bootstrap values and decay values of more than or equal to three), includes two accessions of $H$. moellendorffii var. subbipinnatum, and $H$. dissectifolium. The third group, "C clade" (supported with $71 \%$ of bootstrap values), comprises several subspecies of $H$. sphondylium and $H$. dissectum. The Maximum likelihood tree with $\mathrm{Ts} / \mathrm{Tv}$ rate ratios of 1.5 was topologically congruent to the parsimony trees (Fig. 1B). The clades recognized in the parsimony analyses were shown in the maximum likelihood tree: clades A, B, other accessions, and clade $\mathrm{C}$.

\section{Discussion}

The genus of Heracleum has a wide distribution in Europe and Asia, and has long been problematic in generic delimitation with other Umbelliferous genera (e.g., Pastinaca, Peucedanum) with strongly dorsally depressed fruits (Pu and Watson, 2005). The features of vittae such as oblanceolated (=clavated) shapes, usually shorter than the length of the mericarp, are the characteristics to separate the genus from other genera (Ohba, 1999; She et al., 2005; Lee, 2007; Yu et al., 2011). As Pu and Watson (2005) suggested, however, these unique characters do not support inclusion of all the Chinese Heracleum into the generic boundaries. Their suggestions were consis- tent with results of molecular phylogenetic studies which have shown the genus to be non-monophyletic (Downie et al., 1998; Zhou et al., 2008). Moreover, infraspecific levels of several species of the genus (i.e., H. moellendorffii and $H$. sphondylium) were recognized and the species can be consequently divided into several subspecies or varieties (Ohba, 1999; Pu and Watson, 2005). The major objective in carrying out this study was to ascertain the taxonomic states and positions of all the possible accessions of Heracleum moellendorffii and its allied taxa comparing putatively related speices in neighboring regions. The scientific name, Heracleum moellendorffii was adopted to describe both Korean and Chinese taxa (Lee, 1980; She et al., 2005; Lee, 2007) while $H$. sphondylium or $H$. lanatum $(=H$. maximum $)$ was chosen to describe Japanese Heracleum moellendorffii (Ohba, 1999; Takahashi, 2009). Furthermore, collections obtained from Kamtchatka and Promorskiy, Russia were defined as $H$. lanatum $(=H$. maximum), endemic taxon to North America (data were obtained from the Genbank accessions). Before more discussions, we first comprised all the above taxa and defined as Heracleum moellendorffii complex. Heracleum moellendorffii was divided into three different varieties on the basis of shapes in pinnation patterns and segment forms of basal leaves, and the presence or absence of dorsal vittae (Pu and Watson, 2005). However, the seven accessions of $H$. moellendorffii investigated in here failed to construct a monophyletic clade while $H$. dissectifolium, $H$. maximum, and $H$. wolongense were included within the clade " $A$ " which was the same phylogeny suggested by Yu et al. (2011). Moreover, two accessions of H. moellendorffii var. subbipinnatum were not nested within the clade. Two accessions of Korean H. moellendorffii were identical in ITS and 5.8S ribosomal DNA sequences, but did not form a clade together with Chinese H. moellendorffii. No inclusion of Korean H. moellendorffii into Chinese ones was reflected by the ITS sequence differences between these two; four nucleotide differences and 0.67 percent of sequence divergences. The second objective of the study was to identify a Heracleum taxon collected in Daeamsan, Korea. Although accessions of Korean $H$. moellendorffii var. moellendorffii had identical ITS sequences, another accession collected from Daeamsan, interestingly, was identical to Russian (Primorskiy) H. maximum $(=H$. lanatum), endemic to North America, in its ITS sequence. Therefore, the Daeamsan accession might be conspecific to $H$. maximum in terms of the current molecular phylogenies. H. maximum is commonly called as 'Cow Parsnip' due to its big sizes in leaf, height, and strong scented features (Constance, 1993). However, some Eurasian taxa of the genus show unclear phylogenetic relationships, and their taxonomic status as a species are unstable as well. In the flora of Japan, H. lanatum (= $H$. maximum) was described as a synonym of $H$. sphon- 
dylium ssp. montanum following Mabberley (1987)'s treatment (Ohba, 1994; 1999). However, H. maximum and $H$. sphondylium ssp. montanum failed to construct a monophyletic clade in this study reflecting that each of these two taxa might be an independent species. Considering $1.67-1.83 \%$ divergence in their ITS and 5.8S ribosomal DNA sequences between the two clades of $H$. maximum and their phylogenetic placements, they need to be treated as distinct species from H. sphondyllium, not a infraspecific taxon of it. Although more samples are needed to clarify Japanese Heracleum moellendorffii complex, an Genbank accession from Japan might be treated as conspecific to or infraspecific taxon of $H$. maximum, which is suggested by small sequence divergence (two nucleotides) with Korean and Russian accessions of $H$. maximum and strong bootstrap value (94\%) and decay values $(\geq 3)$. The second clade "B" comprising two accessions of $H$. moellendorffii var. subbipinnatum and $H$. dissectifolium was reflected by the identity of their ITS sequences and the shared morphological characters such as two-pinnated basal leaves, absence of bracts, lanceolate ultimate segments, solitary vittae below each furrow, clavated vittae extending to $1 / 2$ length of mericarp, as were described in the flora of China ( $\mathrm{Pu}$ and Watson, 2005). From the current molecular phylogenetic study, $H$. moellendorffii var. subbipinnatum could be treated as an independent species separated from H. moellendorffii. The third clade " $\mathrm{C}$ " comprises several subspecies of $H$. sphondylium and $H$. dissectum. Taxonomy of H. moellendorffii has been often complicated with $H$. sphondylium which was reported only to be found in Japan within East Asian regions (Ohba, 1994; 1999). For example, $H$. barbatum ssp. moellendorffii, H. lanatum ssp. moellendorffii, H. moellendorffii var. akasimontanum, H. moellendorffii var. tsurugisanense were all described as subspecies of $H$. spondylium (Ohba, 1999). While morphological differences between $H$. moellendorffii and $H$. sphondylium were not clear, the current ITS sequencesderived phylogeny supports the separation between these two taxa reflected by sequence divergences ranging from 1.67 to 2.33 percent. Considering that each of $H$. fargesii, $H$. forrestii, $H$. hemsleyanaum and $H$. wenchuanense was kept to remain as an species (Pu and Watson, 2005) with even below the $1.0 \%$ in the ITS sequence divergence value among themselves, we can support separation of the ssp. montanum from groups of $H$. sphondylium by the sequence divergence values (1.33-1.50\%). Therefore, we have suggested that $H$. sphondylium ssp. montanum be treated taxonomically as an independent taxon, $\mathrm{H}$. montanum Schleich. ex Gaudin. When focused on Korean accessions, we figured out that accessions of $H$. moellendorffii collected from Cheonggyesan and Taebaek were not different from Chinese accessions of $H$. moellendorffii var. moellendorffii. Secondly, the Heracleum sp. collected from Daeamsan, Korea was identified to $H$. maximum. However, the monophyly of accessions of $H$. maximum was not supported from the current molecular phylogenies, with pairwise sequence divergences ranged from identity to 0.83 precent. In terms of non-monophyly and sequence divergences, intraspecific taxonomy of $H$. maximum might be understood when their genetic diversity of the east Asian countries were investigated along with geographical distributions. In conclusion, quite differences in the ITS sequences of the Korean Heracleum from those of neighboring regions such as China and Japan require much more works and samplings to be done to delimit their species boundaries.

\section{AcKnowledgements}

This research was supported by grants from the new and unrecorded species (vascular plants) discovery project by National Institute of Biological Resources, the Ministry of Environment, Korea. The authors deeply appreciate the contributions of three anonymous reviewers for correcting an earlier draft of this manuscript.

\section{REFERENCES}

Bremer, K. 1998. The limits of amino acid sequence data in angiosperm phylogenetic reconstruction. Evolution 42: 795-803

Constance, L. 1993. Umbelliferae. In: J.C. Hickman (ed.), The Jepson Manual, Higher Plants of California. University of California Press, Berkeley, Los Angeles, and London. pp. 136-166.

Downie, S.R., S. Ramanath, D.S. Katz-Downie and E. Llanas. 1998. Molecular systematics of Apiaceae subfamily Apioideae: phylogenetic analysis of nuclear ribosomal DNA internal transcribed spacer and plastid rpoC1 intron sequences. Amer. J. Bot. 85:563-591.

Doyle, J.J. and J.L. Doyle. 1987. A rapid DNA isolation procedure for small quantities of fresh leaf tissue. Phytochem. Bull. 19:11-15.

Im, R.J. 1998. Apiaceae Lindl. Flora Coreana. Vol. 5. The science and technology publishing house, Pyongyang. pp. 367 (in Korean).

Lee, B.Y. 1998. A phylogenetic study of Apiaceae tribe Caucalideae. Ph.D. thesis, University of Illinois at UrbanaChampaign.

Lee, B.Y. 2007. Heracleum L. In: C.-W. Park(ed.), The Genera of Vascular Plants of Korea. Academy Publishing Co., Seoul. pp. 760-761.

Lee, B.Y. and S.R. Downie. 1999. A molecular phylogeny of Apiaceae tribe Caucalideae and related taxa: inferences based on ITS sequence data. Syst. Bot. 24:461-479. 
Lee, B.Y., G.H. Nam, J.Y. Lee, C.H. Park, C.E. Lim, M.H. Kim, S.J. Lee, T.K. Rho, J.A. Lim, J.E. Han and J.H. Kim. 2011. National List of Species of Korea (Vascular plants). National Institute of Biological Resources, Incheon. pp. 633.

Lee, B.Y., J. Lee and S.C. Ko. 2010. Taxonomic review of the Umbelliferous genus Sium L. in Korea: Inferences based on molecular data. Korean J. Pl. Taxon. 40(4):234-239.

Lee, T.B. 1980. Illustrated Flora of Korea. Hyangmoonsa, Seoul. pp. 592 (in Korean).

Lee, W.T. 1996. Lineamenta Florae Koreae. Academy Press, Seoul. pp. 783 (in Korean).

Ma, Y.H., X.J. He, D.Y. Meng and C.B. Wang. 2005. The phylogeny and the geographical temperate characteristic of Heracleum and Angelica in China. Chin. Wild Plant Resour. 24:18-30.

Mabberley, D.J. 1987. The plant-book. A portable dictionary of the vascular plants. second edition. Cambridge University Press, London. pp. 858.

Ohba, H. 1994. Infraspecific taxa of Heracleum sphondylium L. and H. lanatum Michx. J. Jap. Bot. 69:118-119.

Ohba, H. 1999. Umbelliferae. In: K. Iwatsuki et al. (eds.), Flora of Japan. Vol. 2c. Kodansha, Tokyo. pp. 268-303.

Pimenov, M.J. and M.V. Leonov. 1993. The genera of the Umbelliferae. Royal Botanic Gardens, Kew. London. pp. 105.

Pu, F. and M.F. Watson. 2005. Heracleum L. In: She et al. (eds.), Flora of China. Vol. 14. Science Press and Missouri
Botanic Garden Press, Beijing \& St. Louis. pp. 195-202. She, M.-L., F. Pu, Z. Pan, M.F. Watson, J.F.M. Cannon, I. Holmes-Smith, E.V. Kljuikov, L.R. Phillipe and M.G. Pimenov. 2005. Apiaceae (Umbellieare). Flora of China. Vol. 14. Science Press and Missouri Botanic Garden Press, Beijing \& St. Louis. pp. 1-205.

Swofford, D.L. 2000. PAUP*. Phylogenetic analysis using parsimony. Version 4, beta 4a. Sinauer Associates, Sunderland. M.A.

Takahashi, H. 2009. Geographical distribution patterns of the Apiaceae in Sakhalin and the Kuril islands. Biodiversity and Biogeography of the Kuril Islands and Sakhalin. 3:1-34.

White, T.J., T. Bruns, S. Lee and J. Taylor. 1990. Amplification and direct sequencing of fungal ribosomal RNA genes for phylogenetics. In M.A. Innis, D.H. Gelfand, J.J. Sninsky and T.J. White (eds.), PCR Protocols: a guide to methods and applications. Academic Press, San Diego. pp. 315-322.

Yu, Y., S.R. Downie, X. He, X. Deng and L. Yan. 2011. Phylogeny and biogeography of Chinese Heracleum (Apiaceae tribe Tordylieae) with comments on their fruit morphology. Plant Syst. Evol. 296:179-203.

Zhou, J., H. Peng, S.R. Downie, Z.W. Liu and X. Gong. 2008. A molecular phylogeny of Chinese Apiaceae subfamily Apioideae inferred spacer sequences. Taxon 57:402-416.

Submitted: June 27, 2012, Accepted: August 24, 2012 